\title{
A New Preconcentration Method for the Determination of $\mathrm{Pb}$ and $\mathrm{Ni}$ in Real Samples by Using Amberlite XAD-16 Functionalized With 1,6-bis(2-carboxy aldehyde phenoxy)butane
}

\author{
Elif Varhan Orala, $^{a, *}$, Sait Erdogan ${ }^{b}$, Hamdi Temelc $^{c}$, Berrin Ziyadanogullari ${ }^{\mathrm{b}}$, and Recep Ziyadanogullari ${ }^{\mathrm{b}}$ \\ ${ }^{a}$ Dicle University, Faculty of Pharmacy, Department of Analytical Chemistry, 21280 Diyarbakir, Turkey \\ b Dicle University, Faculty of Science, Department of Chemistry, 21280 Diyarbakir, Turkey \\ ${ }^{\mathrm{c}}$ Dicle University, Faculty of Pharmacy, Department of Pharmaceutical Chemistry, 21280 Diyarbakir, Turkey
}

\section{INTRODUCTION}

Because of environmental protection rulings, the detection of metal ions at trace levels has become essential. However, due to their matrix interferences and low concentrations in the samples, the direct determination of metal ions at trace quantities is limited (1-3). Thus, to ensure precision and accuracy of the analytical results, preliminary concentration and matrix removal steps are required. To this end, many methods have been proposed and applied for the pre-concentration and separation of trace elements depending on the type of samples, the concentration of the analytes, and the measurement techniques used. The methods include liquid-liquid extraction $(4,5)$, ion exchange techniques $(6)$, coprecipitation $(7,8)$, cloud point extraction (9), solid phase extraction $(10,11)$, electroanalytical techniques (12), and the chemical and biosorption techniques (13-15). With respect to the various preconcentration methods available, solid phase extraction (SPE) has some advantages because it offers selectivity, good consistency, high concentrating competency, and high sorption capacity of the metal ions.

The multifarious SPE methods have been utilized successfully for the separation and preconcentration of lead and nickel ions at trace

* Corresponding autbor.

E-mail: evarban@dicle.edu.tr

Tel: $+904122411000 / 7543$

Fax: +904122488499

\section{ABSTRACT}

In this study, a steady chelating resin matrix was formed by tying 1,6-bis(2-carboxy aldehyde phenoxy) butane to Amberlite $\mathrm{XAD}-16$ resin by a $-\mathrm{C}=\mathrm{N}$ - group. This synthesized adsorbent was placed into a minicolumn to separate and preconcentrate the lead and nickel ions before their determination by flame atomic absorption spectrometry (FAAS). The effects of many parameters on the preconcentration method were examined. The optimal $\mathrm{pH}$ value for the quantitative absorption of lead and nickel was $\mathrm{pH}$ 5.0. The percentage of recovery for lead and nickel was $99 \pm 1.15 \%$ and $100 \pm 2.70 \%$, respectively. The detection limits of lead and nickel utilizing FAAS $(3 \mathrm{~s}, \mathrm{~N}=20)$ were 1.47 and $1.16 \mu \mathrm{g} / \mathrm{L}$, respectively. The effects of some matrix components on the recovery were analyzed. The suggested method was utilizied to determine lead and nickel in real water samples obtained from the River Tigris in Turkey, as well as in automobile exhaust particles, Romaine lettuce, and parsley. The accuracy of the proposed method was verified by using the standard addition method and the standard reference material NCS-DC 73350 Poplar Leaves.

quantities (16-22). The adsorbent materials used for SPE to preconcentrate the nickel and lead ions are the Amberlite XAD resins (2325), chromosorb resin (26), activated carbon (27), silica gel (28, 29), multiwalled carbon nanotubes (30), biological materials such as bacteria (31), ion-exchange resins (32), and chelating resins (33).

Lead and nickel are toxic elements. The most significant sources of lead exposure for humans are automobile exhaust gases, industrial emissions, contaminated foods, and soils. When vegetables, such as spinach and cabbage, are grown near lead sources, they can absorb the metal and become highly toxic (8). If the lead levels in the blood exceed the daily prescribed minimum amount of $0.5-0.8 \mu \mathrm{g} / \mathrm{mL}$, various abnormalities can develop such as heavy hematological damage, kidney malfunctioning, brain damage, anaemia, etc. (8). Some occupations result in breathing in nickel and its compounds which can cause serious respiratory system syndromes (34). Dermal contact of nickel can lead to a skin disease known as nickeleczema (34-36). Various studies have been published which characterize nickel poisoning as an occupational disorder, specifically found in laborers handling large amounts of this element. Determination of nickel in the urine and blood is used for medical diagnosis. Other studies (34-36) report that the frequency of disorder increases in patients who eat foods rich in nickel. Therefore, it becomes paramount to develop sensitive methods for the determination of nickel in foods.

In the current study, 1,6-bis(2carboxy aldehyde phenoxy)butane was combined with the commercially available polystyrene-divinyl benzene co-polymer Amberlite 
XAD-16 by an $-\mathrm{C}=\mathrm{N}$ - group. In the analysis of trace elements, this kind of functional polymer can be utilized for the preconcentration of geological and biological samples. The above mentioned synthesized adsorbent was added into a minicolumn and used for the separation and preconcentration of $\mathrm{Pb}$ (II) and $\mathrm{Ni}$ (II) before their determination by flame atomic absorption spectrometry (FAAS) $(3,8)$.

The effects of the experimental parameters were studied, such as flow rate, volume, electrolyte effect, stability of the column, amount of Amberlite XAD-16, detection limit, etc. The proposed method was utilized for the analysis of real water samples obtained from the Tigris River, Romaine lettuce, parsley, and automobile exhaust particles. In addition, the accuracy of the method was verified by using standard addition and the standard reference material NCS-DC 73350 Poplar Leaves (China National Analysis Center for Ion and Steel, P.R. China).

\section{EXPERIMENTAL}

\section{Instrumentation}

The columns, equipped with polypropylene frits $(1.0 \mathrm{~cm} \times 10.0$ $\mathrm{cm}$ ), were used for infiltration of SPE. A PerkinElmer ${ }^{\circledR}$ AAnalyst $^{\mathrm{TM}}$ 400 flame atomic absorption spectrometer was used for the determination of $\mathrm{Pb}$ and $\mathrm{Ni}$ (PerkinElmer, Inc., Shelton, CT, USA). The instrumental parameters are listed in Table I. A Mettler Toledo pH-meter, equipped with a glass electrode for measuring the $\mathrm{pH}$ values, was used. The analysis of the synthesized adsorbent functional groups was performed using a Mattson 1000 model FT-IR spectrometer and the elemental analyses were carried out with a model EA1108CHNS-O Element Analyzer (Fisons Instruments, USA ).

\section{Reagents and Solutions}

All of the chemicals used were of analytical grade. The stock solutions of lead and nickel were prepared by dissolution of a suitable amount of metal ions and adding doubly distilled water obtained with a Milli-Q ${ }^{\mathrm{TM}}$ water purification system (Millipore Corporation, USA) into a 100-mL flask. The diluted reference solutions were made daily using a suitable dilution of the stock solution in doubly distilled water. The $\mathrm{pH}$ levels were adjusted by addition of 0.001-0.5 mol/L $\mathrm{HNO}_{3}$ or $\mathrm{NaOH}$.

The Amberlite XAD-16 resin has a specific area of about $800 \mathrm{~m}^{2} \mathrm{~g}^{-1}$ whose pore diameter is $10 \mathrm{~nm}$ and a bead size of 20-60 mesh (Sigma Aldrich, St. Louis, MO, USA). After removal of the chlorides by washing them with distilled water, $4 \mathrm{~mol} / \mathrm{L} \mathrm{HCl}$ solution was added to purify the resin, then it was washed with an ethanol-water solution (1:1), and at the end again with doubly distilled water. Following these processes, the resin was dried in a vacuum oven at $60^{\circ} \mathrm{C}$, then put into a polyethylene bottle. $10 \%$ nitric acid was applied to all of the chemical tools (bottles, columns, flasks, tubes) and left standing overnight, then rinsed twice with doubly distilled water before use (37).

\section{Synthesis of Adsorbent}

$10 \mathrm{~mL}$ each of concentrated nitric acid solution and concentrated sulfuric acid solution was added to

\section{TABLE I}

Operating Conditions of FAAS Instrument

\begin{tabular}{lcc}
\hline Parameters & $\mathrm{Pb}$ & $\mathrm{Ni}$ \\
\hline $\begin{array}{c}\text { HC lamp } \\
\text { current }\end{array}$ & $10 \mathrm{~mA}$ & $25 \mathrm{~mA}$
\end{tabular}

Wavelength $283.31 \mathrm{~nm} 232.00 \mathrm{~nm}$ Flame Air/Acety- Air Acetylene lene the Amberlite XAD-16 beads (2.0 g) and stirred for one hour at $60^{\circ} \mathrm{C}$. Then, the reaction mixture was left standing in an ice and water mixture until precipitation. Initially, the nitrated resin was filtered and then washed again and again with pure water until it became free of acid; at the end, it was treated with a reducing mixture of $16 \mathrm{~g}$ of $\mathrm{SnCl}_{2}$, $18 \mathrm{~mL}$ of concentrated $\mathrm{HCl}$, and $20 \mathrm{~mL}$ of ethanol. The mixture was refluxed for about 12 hours at $90^{\circ} \mathrm{C}$. The altered resin was filtered and washed by using purified water and $2 \mathrm{~mol} / \mathrm{L} \mathrm{NaOH}$ in order to release the amino resin ( $\mathrm{R}-\mathrm{NH}_{2}$ form) from the $\mathrm{R}$ resin matrix $\left(\mathrm{R}-\mathrm{NH}_{3}\right)_{2} \mathrm{SnCl}_{6}$ $(13,23)$.

The amino resin was washed with $100 \mathrm{~mL}$ of $2 \mathrm{~mol} / \mathrm{L} \mathrm{HCl}$ for about 30 minutes, then filtered and washed again with purified water in order to remove the surplus amount of $\mathrm{HCl}$. The amino resin and 1,6-bis(2-carboxy aldehyde phenoxy)butane mixture, synthesized according to the work by Ilhan et al. (38), was put into $50 \mathrm{~mL}$ ethanol, then refluxed at $90{ }^{\circ} \mathrm{C}$ for about 24 hours. Finally, the obtained brown-colored beads, which are Schiff-based, were filtered, washed again with ethanol, then air-dried (see Equation 1).

The acquired data of the $\mathrm{CHN}$ elemental analysis was C 76.12\%, $\mathrm{H} 5.97 \%$, N 5.22\%. There was a possibility of these data to be compared to the theoretically calculated values of $\mathrm{C} 75.98 \%, \mathrm{H} 6.01 \%$, and $\mathrm{N} 5.13 \%$.

\section{Characterization Studies}

The potassium bromide technique was utilized to analyze the infrared spectra of free resin and synthesized adsorbent.

After resin modification with the ligand (Figure 1b), the vibrations different from free resin (Figure 1a) were at the level of about $v(C=N)$ : 1631, v(C-N) : 1368, v(C-O $)_{\text {arom. }}$ : 1291, 1247, v(C-O $)_{\text {alif. }}: 1170,1041$. 
Comparative analysis of the FTIR spectra of the synthesized adsorbent before and after the absorption of lead and nickel indicated that the azomethine group $(>\mathrm{C}=\mathrm{N})$ of the synthesized adsorbent at $1631 \mathrm{~cm}^{-1}$ vibrations were slipped at $5-10 \mathrm{~cm}^{-1}(14,23)$. These observations propose that the chelation comprising the azomethine group is responsible or at least partially liable for the absorption of lead and nickel. It could also be seen that the $\mathrm{C}-\mathrm{O}-\mathrm{C}$ group had a role on the chelation of the lead and nickel. The intensity of the peak changed after the absorption of lead and nickel $(15,24)$. The final proof of chemical bonding was seen by the observation of new bands in the FTIR spectra of the lead and nickel metal complexes which were seen at $520,432 \mathrm{~cm}^{-1}$ and $518,458 \mathrm{~cm}^{-1}$ assigned to $v(\mathrm{~Pb}-\mathrm{O}), v(\mathrm{~Pb}-\mathrm{N})$ and $v(\mathrm{Ni}-\mathrm{O}), v(\mathrm{Ni}-\mathrm{N})$, respectively, stretching vibrations (38) (Figures 1c and 1d). This could be due to the resin displaying significantly high capacity values for the metal ions.

\section{Preparation of Column}

The synthesized adsorbent (about $250 \mathrm{mg}$ ) was wetted with $10 \mathrm{~mL}$ doubly distilled water, then shaken for two hours. The mixture was taken into a polyethylene column of about $1.00 \mathrm{~cm} \times 10.00 \mathrm{~cm}$. $1.0 \mathrm{~mol} / \mathrm{L} \mathrm{HCl}$ solution and doubly distilled water were passed through the column before using it for conditioning and cleaning at the same time. Afterwards, the column was preconditioned with $\mathrm{HCl}$ or $\mathrm{HNO}_{3}$ solution.

\section{Procedure}

The column procedure for this study was examined by using model solutions. The metal solutions, which contain lead and nickel of about $50 \mu \mathrm{g}$ in $50 \mathrm{~mL}$ at the selected pH level, were passed through the column at proper flow rates as specified by the tests.

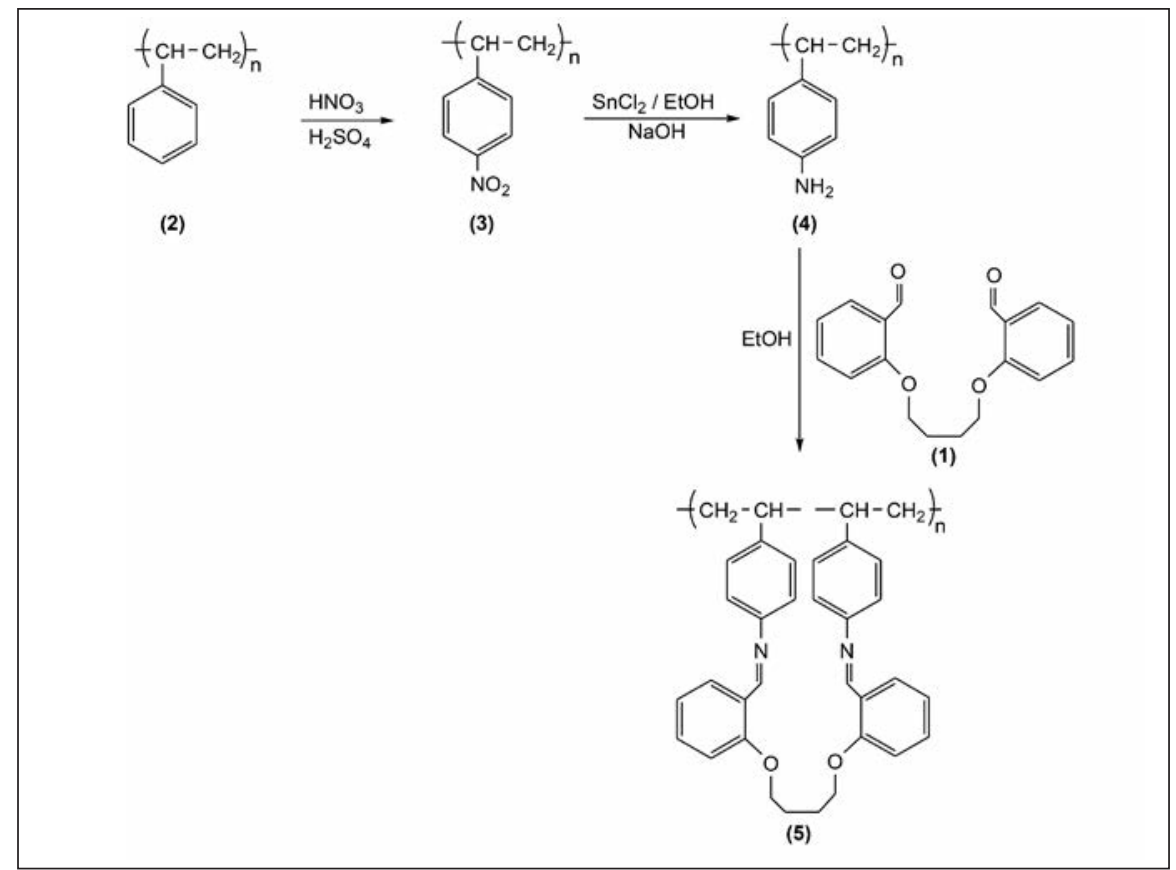

Equation 1. Synthesis of Adsorbent.

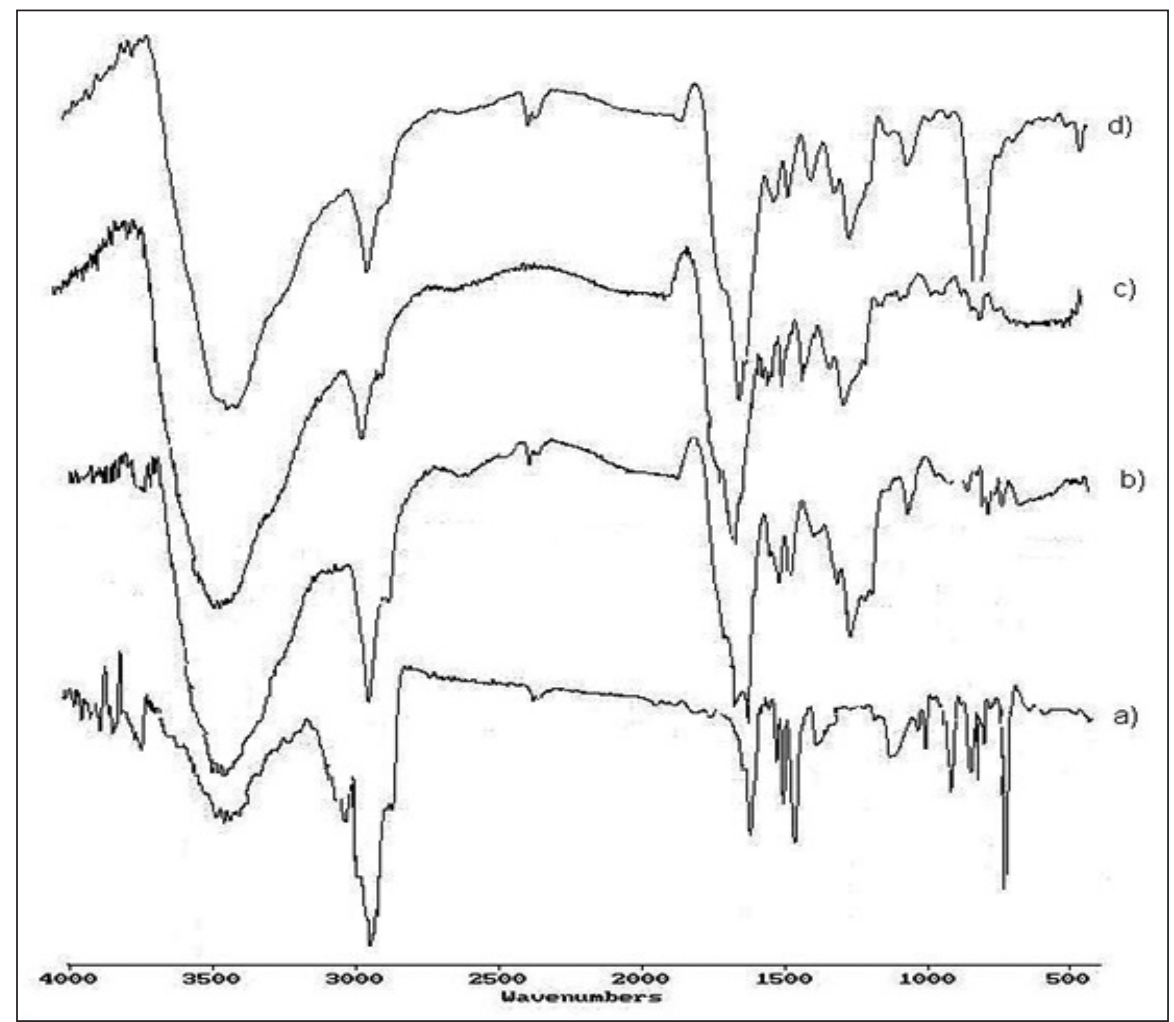

Fig. 1. FT-IR Spectrum of (a)Amberlite XAD-16, (b) Amberlite XAD-16 resin modified by 1,6-bis(2-carboxy aldehyde phenoxy)butane, (c) Amberlite XAD-16-1,6-bis (2-carboxy aldebyde phenoxy)butanes after sorption of nickel, (d) Amberlite XAD16-1,6-bis(2-carboxy aldebyde phenoxy)butanes after sorption of lead. 
Following the passage of the solution through the column, it was rinsed twice with about $10 \mathrm{~mL}$ doubly distilled water. The adsorbed metal ions were eluted by using an appropriate solvent ( $1 \mathrm{~mol} / \mathrm{L} \mathrm{HCl}$ and $\mathrm{HNO}_{3}$ ) which was specified by the tests. Finally, the metal ions were determined using FAAS.

\section{Analysis of Real Samples}

The polyethylene bottles ( $2 \mathrm{~L}$ ), utilized for the analysis of river water, were precleaned with detergent, tap water, doubly distilled water, dilute $\mathrm{HNO}_{3}$, and again doubly distilled water, respectively. The river water samples, taken from two locations of the Tigris river in Diyarbakir and Elazig cities, were filtered through a cellulose membrane having a pore size of about $0.45 \mu \mathrm{m}$, and kept in polyethylene bottles. The river samples were acidified to $1 \%$ by using nitric acid shortly after collection and kept in a refrigerator at $4^{\circ} \mathrm{C}$. To $100 \mathrm{~mL}$ river water samples, $\mathrm{HNO}_{3}$ or $\mathrm{NaOH}$ solutions were added in order to regulate the $\mathrm{pH}$ level. Determination of the analyte ion levels in the final solutions was performed by FAAS.

The particles of automobile exhaust were collected from the roads of Diyarbakır city. Automobile exhaust particles of $0.25 \mathrm{~g}$ were mixed with an acid mixture in a microwave oven for digestion. After the digestion process, the volume was brought to $50 \mathrm{~mL}$ with doubly distilled water. The $\mathrm{pH}$ level of the solution was set by using $\mathrm{HNO}_{3}$ or $\mathrm{NaOH}$ solutions. The analyte ions were determined by FAAS.

The Romaine lettuce sample was taken from an urban garden and the parsley sample was bought from a local store in Diyarbakir city. These samples were cleaned by washing with tap water and doubly distilled water, respectively, then dried at $110{ }^{\circ} \mathrm{C}$, and ground to pass through a 200 mesh sieve. In the microwave oven system, $25 \mathrm{~g}$ each of the Romaine lettuce and parsley samples were digested using concentrated $\mathrm{HNO}_{3}$ and concentrated $\mathrm{H}_{2} \mathrm{O}_{2}$ of about $4 \mathrm{~mL}$ and $2 \mathrm{~mL}$, respectively. Following the digestion process, the volume was increased to $50 \mathrm{~mL}$ by using doubly distilled water. The $\mathrm{pH}$ level of the sample solutions (Romaine lettuce and parsley) was set to optimal, and the samples were passed from the columns at the flow rate of about $4 \mathrm{~mL} / \mathrm{min}$. The elution step was carried out using $1 \mathrm{~mol} / \mathrm{L} \mathrm{HNO}_{3}$ and $1 \mathrm{~mol} / \mathrm{L}$ $\mathrm{HCl}$ for the lead and nickel ions, respectively.

\section{RESULTS AND DISCUSSION}

\section{Influence of $\mathbf{p H}$ on Recovery}

The influence of the aqueous solution $\mathrm{pH}$ on the retention of the metal ions to the synthesized adsorbent highly depends on the hydronium (or hydroxide) ion concentration (aqueous solution ambient). Therefore, the $\mathrm{pH}$ of the metal solutions is one of the most important factors that has a significant effect on their absorption.

For reaching the optimum $\mathrm{pH}$ level for the retention of the trace metal ions, $250 \mathrm{mg}$ synthesized adsorbent was put into a $10-\mathrm{mm}$ i.d. polypropylene column, then $\mathbf{5 0}$ $\mathrm{mL}$ metal solution of $1 \mu \mathrm{g} / \mathrm{mL}$ lead and nickel was passed into it at the optimal flow rate of different $\mathrm{pH}$ values (pH: 2-10). Afterwards, the metal ions were eluted by using $1 \mathrm{~mol} / \mathrm{L} \mathrm{HCl}$. The optimum ranges of $\mathrm{pH}$ for the lead and nickel solutions were found to be 5.8 and 5.6, respectively, as seen in Figure 2.

\section{Influence of Flow Rates}

The metal ion sorption on the $(0.25 \mathrm{~g})$ packed column of the synthesized adsorbent was examined at different flow rates of the metal ion solutions using a peristaltic pump. The metal ion solutions $(50 \mathrm{~mL})$, which includes 50

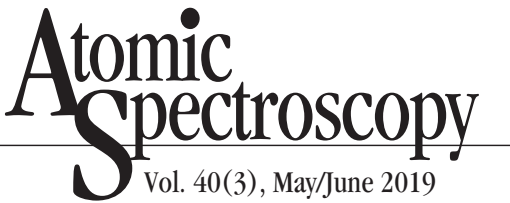

$\mu \mathrm{g}$ of each, were set to optimal $\mathrm{pH}$ value. Afterwards, these solutions were passed through the column at a $1-10 \mathrm{~mL} / \mathrm{min}$ flow rate. As can be seen from Figure 3, two metal ions can be quantitatively sorbed with the adsorbent at the $1.0-4.0 \mathrm{~mL} / \mathrm{min}$ flow rate. In later tests, the flow rate at a speed less than $2.0 \mathrm{~mL} / \mathrm{min}$ was not examined to speed up the analysis. The retrieval of the metal ions was reduced, presumably due to the fact that the metal ions cannot be equilibrated correctly by the adsorbent bed above the level of $4.0 \mathrm{~mL} / \mathrm{min}$. The optimal flow rates for loading lead and nickel onto the synthesized adsorbent was found between 1.0 and $4.0 \mathrm{~mL} / \mathrm{min}$, respectively.

The above mentioned metal ions could be desorbed through the synthesized adsorbent at $1.0-2.0 \mathrm{~mL} / \mathrm{min}$ flow rate quantitatively for desorption, and the recovery for the metal ions was found lower than $95 \%$ above the $2.0 \mathrm{~mL} / \mathrm{min}$ flow rate.

\section{Elution Process}

Other significant factors having an effect on the preconcentration technique are type, concentration, and volume of the elution solutions. Elution of metals from the minicolumn was carried out with $0.25,0.5$, and $1.0 \mathrm{~mol} / \mathrm{L}$ nitric acid and hydrochloric acid solutions; and the volume of the eluent was found at 3, 5 , and $10 \mathrm{~mL}$, respectively. A $10 \mathrm{~mL}$ amount of $1 \mathrm{~mol} / \mathrm{L} \mathrm{HNO}_{3}$ and $\mathrm{HCl}$ was found satisfactory ( $>98 \%$ ) for the recovery of the lead and nickel ions, respectively, as can be seen in Table II.

\section{Effect of Adsorbent Amount}

The recovery and effect of the sorbent's amount on the retention was examined for the two metal ions and the amount of adsorbent was found to be between 100 to $500 \mathrm{mg}$. The amounts of adsorbents used were about 250 and $500 \mathrm{mg}$ for $100 \%$ retention and recovery of the two metals (Figure 4). There- 


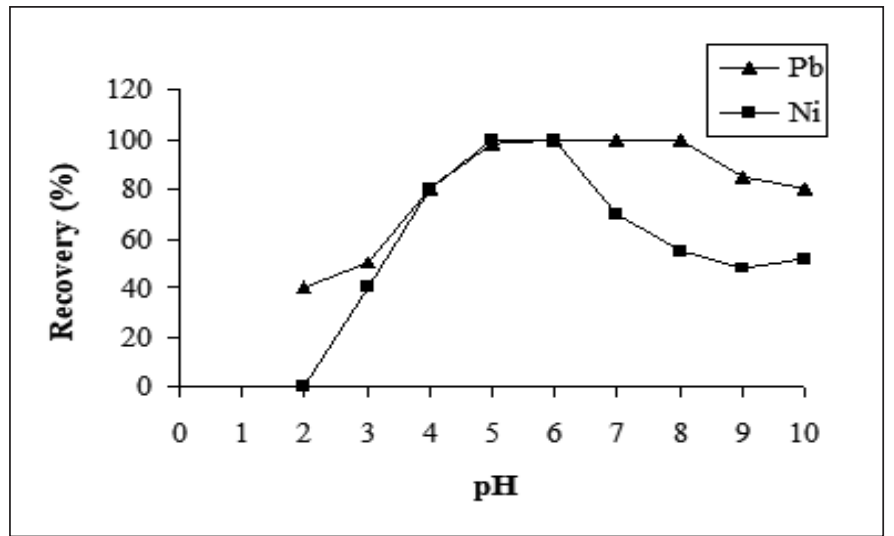

Fig. 2. Effect of $p H$ on recovery of each metal. $\mathrm{Pb}(\mathrm{II}): 1 \mu \mathrm{g} / \mathrm{mL}$, $50 \mathrm{~mL}$, eluent $1 \mathrm{M} \mathrm{HNO}_{3}$; $\mathrm{Ni}(\mathrm{II}): 1 \mu \mathrm{g} / \mathrm{mL}, 50 \mathrm{~mL}$, eluent $1 \mathrm{M}$ HCl. Flow-rate sorption: $4 \mathrm{~mL} / \mathrm{min}$. Flow-rate elution: $1 \mathrm{~mL} / \mathrm{min}$.

\section{TABLE II}

Effect of Type and Volume of Elution Solutions on Recovery of $\mathrm{Pb}$ (II) and $\mathrm{Ni}$ (II).

\begin{tabular}{|c|c|c|c|c|}
\hline $\begin{array}{l}\text { Elution } \\
\text { Solution }\end{array}$ & $\begin{array}{l}\text { Concentration } \\
(\mathrm{mol} / \mathrm{L})\end{array}$ & $\begin{array}{l}\text { Volume } \\
\text { (mL) }\end{array}$ & $\begin{array}{c}\mathrm{Pb}(\mathrm{II}) \\
\text { Recovery } \\
(\%)\end{array}$ & $\begin{array}{c}\mathrm{Ni}(\mathrm{II}) \\
\text { Recovery } \\
(\%)\end{array}$ \\
\hline \multirow[t]{12}{*}{$\mathrm{HCl}$} & 0.25 & 3 & 0 & 48 \\
\hline & & 5 & 0 & 62 \\
\hline & & 10 & 0 & 75 \\
\hline & 0.5 & 3 & 0 & 85 \\
\hline & & 5 & 0 & 90 \\
\hline & & 10 & 0 & 92 \\
\hline & 1.0 & 3 & 84 & 85 \\
\hline & & 5 & 91 & 93 \\
\hline & & 10 & 100 & 100 \\
\hline & 0.25 & 3 & 47 & 45 \\
\hline & & 5 & 60 & 53 \\
\hline & & 10 & 70 & 68 \\
\hline \multirow[t]{6}{*}{$\mathrm{HNO}_{3}$} & 0.5 & 3 & 61 & 72 \\
\hline & & 5 & 70 & 85 \\
\hline & & 10 & 78 & 94 \\
\hline & 1 & 3 & 88 & 83 \\
\hline & & 5 & 93 & 92 \\
\hline & & 10 & 100 & 99 \\
\hline
\end{tabular}

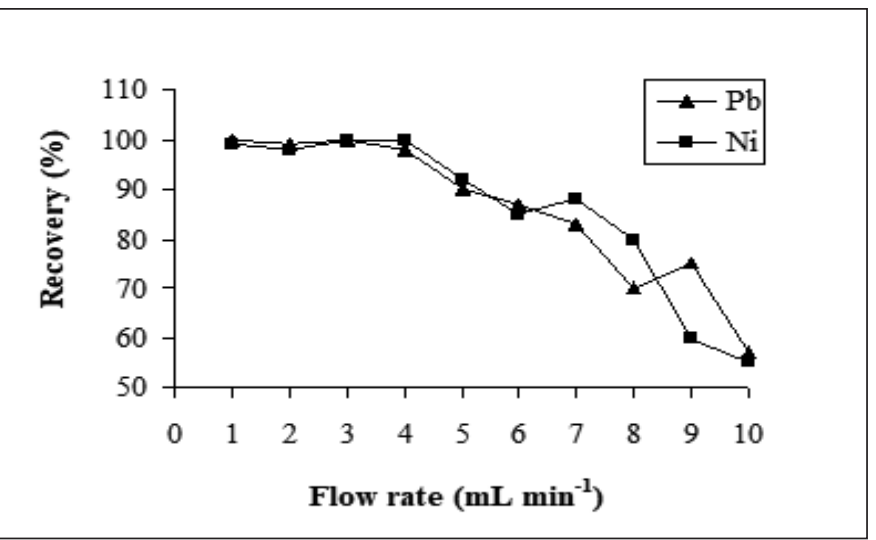

Fig.3. Effect of sample solution flow rate on sorption. Experimental conditions: $\mathrm{Pb}(\mathrm{II}): 1 \mu \mathrm{g} / \mathrm{mL}, 50 \mathrm{~mL}$ pH 5.O, Ni(II) : $1 \mu \mathrm{g} / \mathrm{mL}, 50 \mathrm{~mL} \mathrm{pH} 5$.

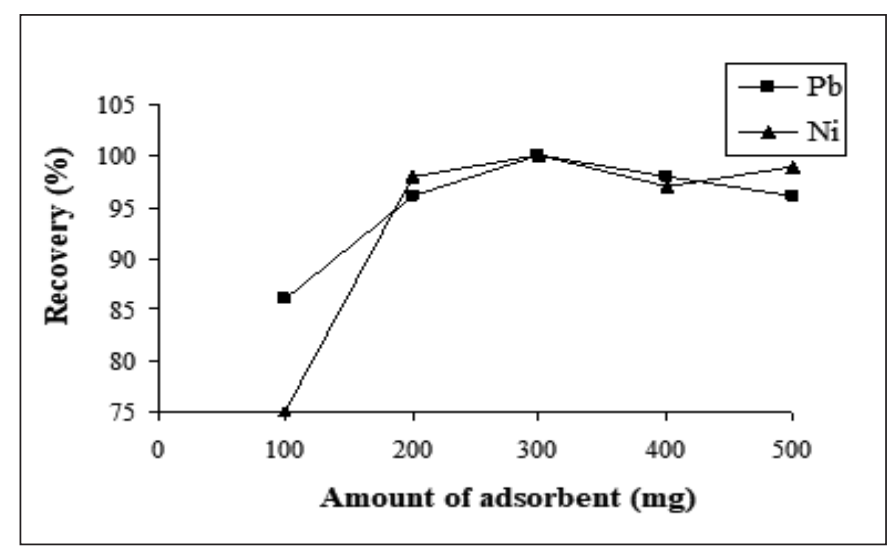

Fig. 4. Effect of amount of adsorbent.

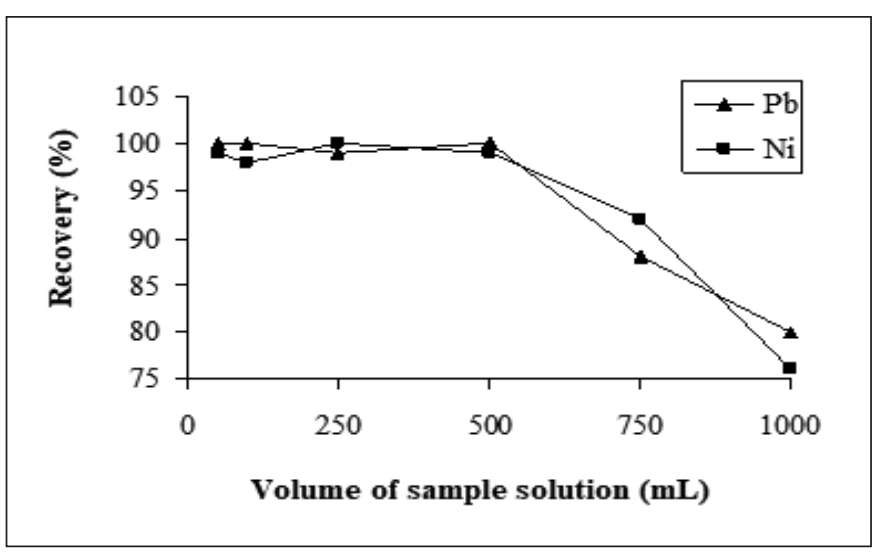

Fig.5. Effect of volume of sample solution. 


\section{Atomic Apectroscopy \\ $\bigcirc$ Vol. 40(3), May/June 2019}

fore, the adsorbent of about 250 mg was utilized for the studied ions in further perconcentration analyses.

\section{Influence of Sample Volume}

The volume of sample solution is a significant parameter for acquiring a high preconcentration factor. The effect of sample solution volume on metal sorption was examined with solution volumes of 50 , 100, 250, 500, 750, and $1000 \mathrm{~mL}$, including $0.25,0.125,0.05,0.025$, $0.017,0.0125 \mu \mathrm{g} / \mathrm{mL}$ of the studied ions, passing from the column at the optimal conditions, respectively. The sample volume of less than $500 \mathrm{~mL}$ did not affect the adsorption of the metal ions. As can be seen from Figure 5, the percentage of sorption was reduced for the analytes in sample solutions exceeding $500 \mathrm{~mL}$. In this study, the elution volume used for the two metal ions was $10 \mathrm{~mL}$. For this reason, the preconcentration factors were found at $\mathbf{1 0 0}$ for each analyte.

\section{Reusability of Synthesized Adsorbent}

In the current study, the metal ions were sorbed and desorbed many times by use of a $50 \mathrm{~mL}$ solution with a concentration about $5-50 \mu \mathrm{g} / \mathrm{mL}$ at optimal testing conditions on $250 \mathrm{mg}$ of synthesized adsorbent. The sorption capacity, reached after about 10 cycles of sorption and desorption, did not change by more than $2.0 \%$ (Figure 6). For this reason, re-usage for resin is probable.

\section{Effect of Electrolytes}

Alkali, alkaline earth, and salts of some transition elements are widely found as being a part in natural water samples. Hence, the effect of electrolytes was examined at different concentrations, and these tests were performed by utilizing $5 \mu \mathrm{g}$ lead and nickel in a volume of $50 \mathrm{~mL}$. Retrieval of the

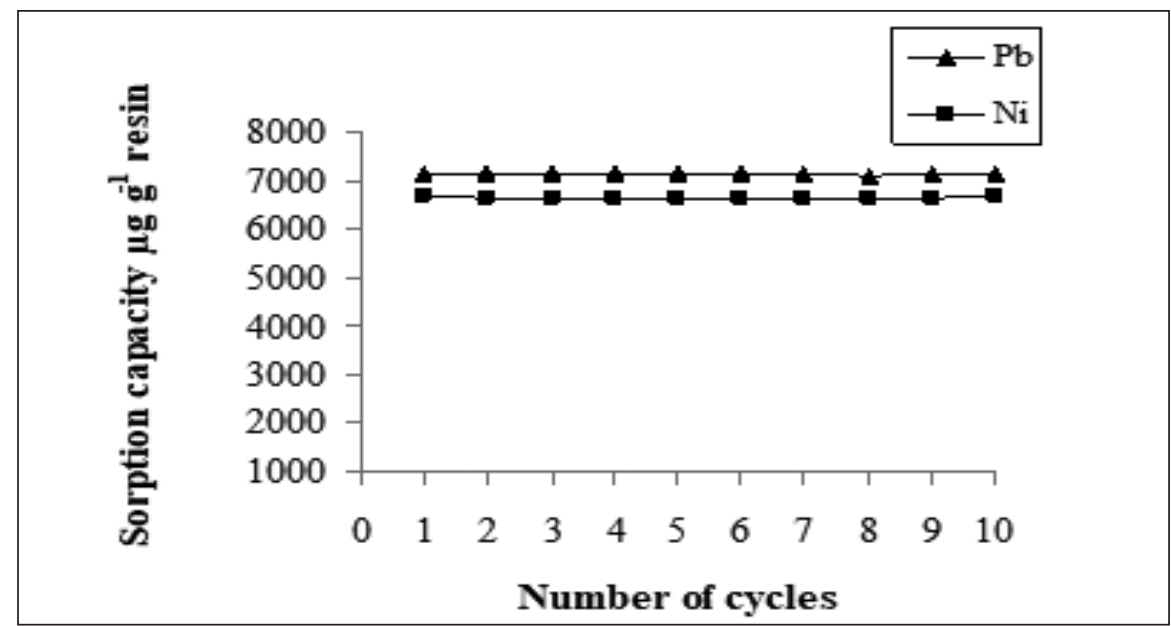

Fig. 6. The effect of column reuse on recovery of Nickel(II) and Lead(II) by Amberlite XAD-16-1,6-bis(2-carboxy aldehyde pbenoxy)butane.

TABLE III Effect of Electrolytes

\begin{tabular}{lrrr}
\hline Ion & $\begin{array}{c}\text { Added Conc. } \\
\left(\mathrm{mg} \mathrm{L}^{-1}\right)\end{array}$ & \multicolumn{2}{c}{ Recovery (\%) } \\
& 1000 & 100.8 & Ni(II) \\
\hline $\mathrm{Na}^{+}$ & 10,000 & 99.6 & 102.6 \\
& 20,000 & 97.2 & 101.2 \\
$\mathrm{~K}^{+}$ & 500 & 100.3 & 98.2 \\
& 1000 & 101.8 & 101.5 \\
& 2000 & 99.2 & 100.0 \\
$\mathrm{Ca}^{2+}$ & 500 & 100.8 & 95.2 \\
& 1000 & 99.7 & 99.8 \\
& 2000 & 95.3 & 95.6 \\
$\mathrm{Mg}^{2+}$ & 250 & 98.5 & 96.6 \\
& 500 & 90.2 & 99.4 \\
& 1000 & 83.2 & 81.6 \\
$\mathrm{Cl}^{-}$ & 1540 & 100.8 & 74.00 \\
& 15,400 & 99.6 & 102.6 \\
& 30,800 & 97.2 & 101.2 \\
$\mathrm{SO}_{4}^{2-}$ & 995 & 98.5 & 98.2 \\
& 1990 & 90.2 & 99.4 \\
& 3980 & 83.2 & 81.6 \\
& & & 74.00 \\
\hline
\end{tabular}

analytes with different metal ion concentrations is listed in Table III. The results of the studies show that the metals of $\mathrm{Na}^{+}, \mathrm{K}^{+}, \mathrm{Ca}^{+2}, \mathrm{Cl}^{-}$did not cause any important decrease in the recovery of the analytes.
Besides that, the concentration of $250 \mathrm{mg} / \mathrm{L} \mathrm{Mg}^{+2}$ and $1000 \mathrm{mg} / \mathrm{L}$ $\mathrm{SO}_{4}^{-2}$ caused an important decrease for the recovery of the analytes. The electrolytes, which are in the solutions, have a general negative 
effect on the metal uptake of the resin due to the competition for binding sites among similarly charged ions.

\section{Total Sorption Capacity}

The following procedure specified the total capacity of metal ion sorption: The synthesized adsorbent of about $0.25 \mathrm{~g}$ was initially put into a column, then a suitable aliquot of metal ion solution was passed through the column at the optimal test conditions (flow rate, $\mathrm{pH}$, etc.). When the synthesized adsorbent was saturated, the concentration of the metal ions was specified by FAAS. The capacities of lead and nickel were found at the amounts of 0.0344 and 0.113 $\mathrm{mmol} / \mathrm{g}$, respectively, and the results are listed in Table IV.

\section{Accuracy of Proposed Method}

The standard reference material NCS-DC 73350 Poplar Leaves and the standard addition method used for real life samples were examined by assessing the precision of the procedure developed, and the confidence intervals were found at the level of $96 \%$. The measurements of nickel and lead specified in the standard reference material are compatible with the certified values (see Table V). Moreover, the direct analytical results of the studied metal ions in the real samples and the results of the standard addition method were very close to each other, showing that the results indicate reliability of the developed method (Table VI).

\section{Analysis of Real Samples}

In order to control the practicability of the recommended method for the preconcentration and determination of the lead and nickel ions, the adsorbent was also exposed to real samples taken from two different locations of the Tigris River, the Romaine lettuce and parsley were grown in Diyarbakır city, and the automobile exhaust
TABLE IV

Total Sorption Capacity of Metal Ions on Amberlite XAD16-1,6-bis(2-carboxy aldehyde phenoxy)butane

\begin{tabular}{ccc}
\hline Metal Ion & \multicolumn{2}{c}{ Capacity } \\
& $(\mu \mathrm{g} / \mathrm{g})$ & $(\mathrm{mmol} / \mathrm{g})$ \\
\hline $\mathrm{Pb}(\mathrm{II})$ & 7136 & $3.44 \times 10^{-2}$ \\
$\mathrm{Ni}(\mathrm{II})$ & 6656 & $11.3 \times 10^{-2}$ \\
\hline
\end{tabular}

TABLE V

Determination of $\mathrm{Pb}$ (II) and Ni(II) in Certified Sample

\begin{tabular}{lcc}
\hline Analyte & $\begin{array}{c}\text { Certified } \\
\text { Value }^{\mathrm{a}} \\
(\mu \mathrm{g} / \mathrm{g})\end{array}$ & $\begin{array}{c}\text { Found by } \\
\text { Present Method } \\
(\mathrm{mmol} / \mathrm{g})\end{array}$ \\
\hline $\mathrm{Pb}$ & 1.50 & $1.53 \pm 0.02$ \\
$\mathrm{Ni}$ & 1.90 & $1.95 \pm 0.04$ \\
\hline${ }^{\mathrm{a}}$ Certified Reference Material \\
(Leaves of Poplar -NCS-DC 73350). \\
b Average of N determinations with \\
95\% confidence level, R \pm ts/ $\mathrm{N}$. \\
$\mathrm{N}=5$
\end{tabular}

TABLE VI

Application of Standard Addition Method to Sample From Tigris River

\begin{tabular}{ccccc}
\hline Metal Ion & $\begin{array}{c}\text { Added } \\
(\mu \mathrm{g} / \mathrm{L})\end{array}$ & $\begin{array}{c}\text { Found } \\
(\mu \mathrm{g} / \mathrm{L}) \\
\mathrm{R} \pm \mathrm{ts} / \sqrt{\mathrm{N}}\end{array}$ & $\begin{array}{c}\mathrm{RE}^{\mathrm{a}} \\
(\%)\end{array}$ & $\begin{array}{c}\mathrm{RSD}^{\mathrm{b}} \\
(\%)\end{array}$ \\
\hline $\mathrm{Pb}$ (II) & 0 & $176.26 \pm 2.18$ & - & 1.08 \\
& 100 & $282.80 \pm 2.00$ & +2.40 & 0.61 \\
$\mathrm{Ni}$ (II) & 0 & $13.78 \pm 1.06$ & - & 6.68 \\
& 25 & $37.03 \pm 0.22$ & -4.51 & 0.51 \\
\hline
\end{tabular}

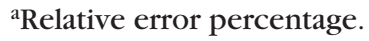

${ }^{\mathrm{b}}$ Relative standard deviation.

TABLE VII

Concentration of Analyte Ions in Natural Water Samples as $\mu \mathrm{g} / \mathrm{L}$ ( $N=5$, sample volume $500 \mathrm{~mL}$, final volume: $5 \mathrm{~mL}$ )

\begin{tabular}{lcc}
\hline Water Samples & $\begin{array}{c}\mathrm{Pb}(\mathrm{II}) \\
\mathrm{R} \pm \mathrm{ts} / \sqrt{ } \mathrm{N}\end{array}$ & $\begin{array}{c}\mathrm{Ni}(\mathrm{II}) \\
\mathrm{R} \pm \mathrm{ts} / \sqrt{ } \mathrm{N}\end{array}$ \\
\hline Tigris River water in Diyarbakir & $176.26 \pm 2.18$ & $13.78 \pm 1.06$ \\
Tigris River water in Elazig & $97.80 \pm 1.31$ & $14.50 \pm 1.10$ \\
\hline
\end{tabular}

$\mathrm{N}=5$

particles were taken from high level traffic density locations.

The above mentioned real samples were digested with a closed microwave oven system and later the method of preconcentration/ separation mentioned in the Analysis of Real Samples section was utilized. The concentrations of the ions examined in this study were at the $\mu \mathrm{g} / \mathrm{g}$ levels and the results are listed in Tables VII and VIII.

\section{Precision of the Method}

The optimal conditions mentioned above were selected for obtaining the precision of the recommended method. Therefore, the relative standard deviations of five different measurements were percontaining $1.00 \mu \mathrm{g} / \mathrm{mL}$ lead and nickel, respectively. These metals were specified in the solution by using FAAS. The retrievals of lead and nickel were quantitative, and show extremely good precision (see Table IX). formed for the sample solutions 
TABLE VIII

Application of Present Method to Microwave-digested Samples for $\mathrm{Pb}$ and $\mathrm{Ni}$ Detrmination $(\mu \mathrm{g} / \mathrm{g}, \mathrm{N}=5)$

\begin{tabular}{lcc}
\hline & $\mathrm{Pb}(\mathrm{II})$ & $\mathrm{Ni}(\mathrm{II})$ \\
$\mathrm{R} \pm \mathrm{ts} / \sqrt{\mathrm{N}}$ & $\mathrm{R} \pm \mathrm{ts} / \mathrm{N}$ \\
\hline Automobile exhaust particles & $8.38 \pm 0.32$ & $\mathrm{nd}^{\mathrm{a}}$ \\
Romaine lettuce & $5.56 \pm 0.50$ & $\mathrm{nd}^{\mathrm{a}}$ \\
Parsley & $4.12 \pm 0.17$ & $\mathrm{nd}^{\mathrm{a}}$ \\
\hline
\end{tabular}

${ }^{a}$ nd: not detected.

$\mathrm{N}=5$

TABLE IX

Precision of Method

\begin{tabular}{ccc}
\hline Element & Recovery $^{\mathrm{a}}(\%)$ & $\mathrm{N}$ \\
\hline $\mathrm{Pb}(\mathrm{II})$ & $99 \pm 1.15$ & 5 \\
$\mathrm{Ni}(\mathrm{II})$ & $100 \pm 2.70$ & 5 \\
\hline
\end{tabular}

${ }^{a}$ Average of $\mathrm{N}$ determinations with

$95 \%$ confidence level, $\mathrm{R} \pm \mathrm{ts} / \mathrm{V} \mathrm{N}$

\section{Detection Limit}

The detection limits of lead and nickel by FAAS (evaluated as the concentration corresponding to three times the standard deviation of the blank signal ( $3 \mathrm{~s}), \mathrm{N}=20$ ) were found to be 1.47 and 1.16 $\mu \mathrm{g} / \mathrm{L}$, respectively.

\section{CONCLUSION}

This study describes the use of a new and good synthesized adsorbent which was covalently linked in 1,6-bis(2-carboxy aldehyde phenoxy)butane with the Amberlite XAD-16 for enriching the trace levels of lead and nickel in real samples. There is also the possibility for the effective separation of the metals from different electrolytes. In addition, this method is simple, reliable, and accurate.

The adsorbent capacities for nickel and lead were about 0.344 and $0.113 \mathrm{mmol} / \mathrm{g}$, respectively, and the possibility for reusability of the synthesized adsorbent was more than 10 cycles. Also no loss in the sorption behavior was found. The preconcentration of the metal ions in high sample volumes was also achieved. The recommended procedure was applied for the determination of lead and nickel ions in real samples such as water from two locations on the Tigris River, automobile exhaust particles, Romaine lettuce, and parsley grown locally. The precision of the recommended method was verified by assaying the standard addition method and analyzing a standard reference material. The obtained results were comparable with the certified values, and the results of the direct and standard addition methods verify the reliability of the results for metal analysis in natural samples.

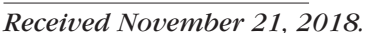

\section{REFERENCES}

1. Y. Guo, B. Din, Y. Liu, X. Chang, S. Meng, and J. Liu, Talanta 62, 209 (2004).

2. M. Ghaedi, F. Ahmadi, and M. Soylak, J. Hazard. Mater. 147, 226 (2007).

3. M. Dogru, R. Gul-Guven, and S. Erdogan, J. Hazard. Mater. 149, 166 (2007).

4. C. Hamamci, H. Hosgören, and S. Erdogan, Talanta 47, 229 (1998).

5. B. Ziyadanogulları, G. Topal, S. Erdogan, C. Hamamci, and $\mathrm{H}$. Hoşgoren, Talanta 153, 1083 (2001).

6. W. Li, H. Zhao, D.R. Teasdale, N. John, and S. Zhang, Anal. Chim. Acta 464, 331 (2002).
7. M. Soylak, S. Saracoglu, U. Divrikli, and L. Elci, Talanta 66, 1098 (2005).

8. T. Oymak, S. Tokalioglu, V. Y1lmaz, S. Kartal, and D. Aydın, Food Chem. 113, 1314 (2009).

9. Y. Yamini, M. Faraji, S. Shariati, R. Hassani, and M. Ghanbarian, Anal. Chim. Acta. 612, 144 (2008).

10. V.V. Khasanov, A.I. Makarycheva, and Yu. G. Slizhov, J. Anal. Chem. 71, 1028 (2016).

11. Q.F. Hu, G.Y. Yang, J.H. Yang, and J.Y. Yin, J. Environ.Monitor 4, 956 (2002).

12. S. A. Özkan, B. Uslu, and H. Y. Aboul-Enein, Crit. Rev. Anal. Chem. 33, 155 (2003)

13. M. Kumar, D.P.S. Rathore, and A.K. Singh, Talanta 51, 1187 (2000).

14. G. Venkatesh, and A.K. Singh, Talanta 67, 187 (2005).

15. O.D. Uluozlu, A. Sari, M. Tuzen, and M. Soylak, Bioresorce Tech. 99, 2972 (2008).

16. M. Tuzen, M. Soylak, and L. Elci, Anal. Chim. Acta 548, 101 (2005).

17. Z.A. Alothman, Y.E. Unsal, M. Habil, M. Tuzen, M. Soylak, Desalination and Water Treatment 53, 3457 (2015).

18. S. Khazaeli, N. Nezamabadi, M. Rabani, and H.A. Panahi, Microchem. J. 106, 147 (2013).

19. M. Soylak, and M. Tuzen, J. Hazard. Mat. B137, 1496 (2006).

20. M. Tuzen, K.O. Saygi, M. Soylak, J. Hazard. Mat. 152, 632 (2008).

21. A. Duran, M. Tuzen, and M., Soylak, J. Hazard. Mat. 169, 466 (2009).

22. M. Tuzen, K.O. Saygi, and M. Soylak, Bioresorce Technol. 99, 1563 (2008).

23. P.K. Tewari, and A.K. Singh, Analyst 124, 1847 (1999).

24. D. Kara, A. Fisher, and S.J. Hill, Analyst 131, 1232 (2006).

25. V.N. Bulut, A. Gundogdu, C. Duran, H.B. Senturk, M. Soylak, L. Elci, and M. Tufekci, J. Hazard. Mat. 146, 155 (2007). 
26. M. Tuzen, K. Parlar, and M. Soylak, J. Hazard. Mat. B121, 79 (2005).

27. R. Gao, Z. Hu, X. Chang, Q. He, L. Zhang, Z. Tu, and J. Shi, J. Hazard. Mat. 172, 324 (2009).

28. M. Alan, A.S. Fisher, and D. Kara, Sep. Sci.Technol. 42, 879 (2007)

29. S. Feng, Z. Guo, J. Fan, X. Chen, and J. Sun, Microchim. Acta. 149, 61 (2005)

30. H. Katsumata, H. Kojima, S. Kaneco, T. Suzuki, and K. Ohta, Microchem. J. 96, 348 (2010).

31. I. Yener, E. Varhan Oral, I. Dolak, S. Ozdemir, and R. Ziyadanogullari, Ecol. Eng. 103, 43 (2017).
32. Y. Rodriguez, and J.F. Tyson, J. Anal. At. Spectrom. 21, 757 (2006).

33. A.O. Martins, E.Luiz da Silva, M.C. Laranjeira, and V.T. de Favere, Microchim. Acta 150, 27 (2005).

34. S.L.C. Ferreira, W.N.L. dos Santos, and V.A. Lemos, Anal. Chim. Acta 445, 145 (2001).

35. J. Kristiansen. J.M. Cristensen, T. Henriksen, N.H. Nielsen, and T. Menne, Anal. Chim. Acta 403 265 (2000).

36. J.M. Cristensen, J. Kristiansen, N.H. Nielsen, T. Menne, and K. Byrialsen, Toxicol. Lett. 108, 185 (1999).
37. S. Erdogan, M. Merdivan,

C. Hamamci, O. Akba, and

A. Baysal, Anal. Lett. 37, 2565

(2004).

38. S. Ilhan, H. Temel, and A. Kilic, J. Coord. Chem. 61, 277 (2008)

\section{* CRC Press/Taylor \& Francis announces the availability of *}

\section{Measuring Elemental Impurities in Pharmaceuticals: A Practical Guide}

\section{Robert J. Thomas, CSci, CChem, FRSC Principal Consultant Scientific Solutions Gaithersburg, MD}

- The complete guide to measuring elemental impurities in pharmaceutical and nutraceutical materials.

- Covers heavy metals testing in the pharmaceutical industry from an historical perspective.

- Gives an overview of current USP Chapters <232><233> and <2232> and ICH Q3D Step 4 Guidelines.

- Explains the purpose of validation protocols used in Chapter <233>, including how J-values are calculated

- Describes fundamental principles and practical capabilities of ICP-MS and ICP-OES.

- Offers guidelines about the optimum strategy for risk assessment.

- Provides tips on how best to prepare and present your data for regulatory inspection.

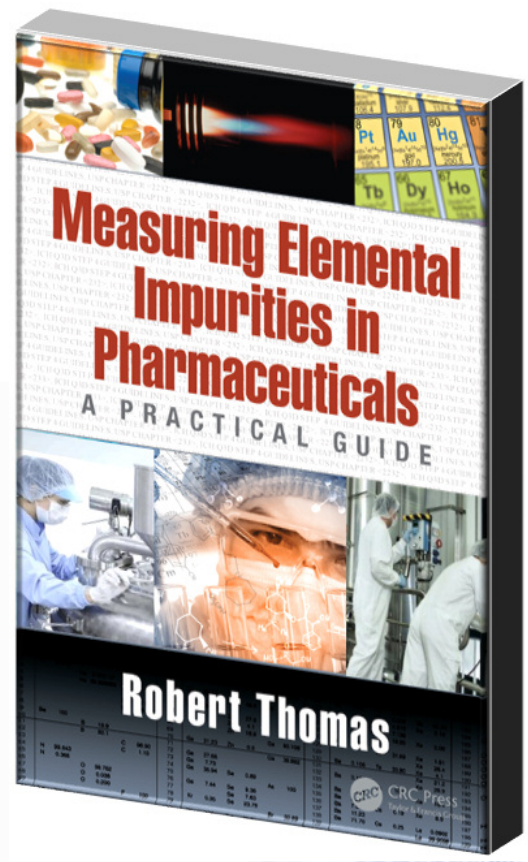

